\title{
Estresse hídrico simulado em genótipos de feijão, milho e soja
}

\author{
Karen Andreon Viçosi ${ }^{1}$, Aparecido Alves Serafim Ferreira ${ }^{1}$, Luis Augusto Batista de \\ Oliveira $^{2}$, Fabrício Rodrigues ${ }^{1}$ \\ ${ }^{1}$ Universidade Estadual de Goiás, Câmpus Ipameri, Ipameri, Goiás, Brasil. E-mail: karen_vicosi@ @otmail.com, \\ aparecido.asf@hotmail.com, fabricio.rodrigues@ueg.br \\ ${ }^{2}$ Universidade Estadual de Goiás, Câmpus Porangatu, Porangatu, Goiás, Brasil. E-mail: luisaugusto-1993@hotmail.com
}

Recebido: 04/06/2017; Aceito: 05/09/2017.

\section{RESUMO}

O trabalho teve como objetivo simular condições de déficit hídrico, em laboratório, por meio do manitol, para avaliação do desempenho fisiológico de sementes de cultivares de feijão, milho e soja. As sementes foram submetidas à germinação sob condições de estresse hídrico, com os níveis $0,-0,6,-1,2,-1,8$ e -2,4 MPa de potencial osmótico, simulados com soluções de manitol $\left(\mathrm{C}_{6} \mathrm{H}_{14} \mathrm{O}_{6}\right)$, nas doses: $0 ; 44 ; 58 ; 89,17 ; 133,75 \mathrm{~g} \mathrm{~L}^{-1}$. Para cada espécie, foi utilizada quatro repetições por tratamento, composta de 50 sementes colocadas em três folhas de papel Germitest, umedecida com solução de manitol correspondente a 2,5 sua massa, e levadas a uma câmara de germinação por 10 dias. O feijão foi a cultura com maior sensibilidade ao déficit hídrico, com redução da germinação, comprimento do hipocótilo e da radícula a $-0,6 \mathrm{MPa}$, enquanto o milho e soja tiveram sua germinação afetada em potencias abaixo de $-1,2 \mathrm{MPa}$. A redução no potencial hídrico afetou negativamente o comprimento da radícula e do hipocótilo para as três culturas em potencial de -0,6 MPa. A germinação e comprimento do hipocótilo e da radícula para feijão, milho e soja são reduzidos sob condições de estresse hídrico e salino induzidos por manitol e existe comportamento diferenciado das espécies estudadas quanto à tolerância à condição de déficit hídrico.

Palavras-chave: potencial osmótico, sementes, manitol.

\section{Simulated water stress in common bean, corn and soybean genotypes}

\begin{abstract}
The objective of this work was to evaluate the physiological performance of seeds of bean, corn and soybean cultivars in the laboratory using mannitol. The seeds were submitted to germination under conditions of water stress, with levels $0,-0.6,-1.2,-1.8$ and $-2.4 \mathrm{MPa}$ of osmotic potential, simulated with solutions of mannitol $\left(\mathrm{C}_{6} \mathrm{H}_{14} \mathrm{O}_{6}\right)$, At doses: $0 ; 44 ; 58 ; 89.17 ; 133.75 \mathrm{~g} \mathrm{~L}^{-1}$. For each species, four replicates are used per treatment, consisting of 50 seeds placed on three sheets of Germitest paper, moistened with mannitol solution corresponding to 2.5 mass, and taken to BOD for 10 days. The bean was a crop with greater sensitivity to water deficit, with reduction of germination, length of hypocotyl and radicle at $-0,6 \mathrm{MPa}$, while corn and soybean had their germination affected in potencies below -1,2 MPa. Non-potential aphid reduction negatively affected radicle and hypocotyl length for the three potential cultures of -0.6 MPa. Germination and length of the hypocotyl and radicle for beans, maize and soybean are reduced under conditions of mannitol - induced water and saline stress, and there is a differentiated behavior of the species studied regarding the tolerance to the water deficit condition.
\end{abstract}

Key words: osmotic potential, seeds, mannitol. 


\section{Introdução}

A água é uma das substâncias chave para manutenção da vida no planeta, atuando como um solvente universal e como um transportador de gases, elementos e substâncias, essenciais para animais e plantas (RODRIGUES et al., 2016). Na agricultura é um dos componentes de suma importância durante o processo de transformação de energia em alimento (TAIZ; ZEIGER, 2008), presente em grande parte das reações que mediam a produção de alimento. Dessa forma, levando em consideração a altíssima demanda de alimentos, a utilização da água no contexto agrícola é indispensável (KIRSANOVA et al., 2013).

Meireles et al. (2010) afirmam que a disponibilidade de água nos últimos anos foi gravemente afetada devido ao aumento das áreas irrigadas, resultando num cenário cada vez mais frequente de escassez hídrica. Esta escassez em certas regiões do país associada às transições climáticas bruscas, acabam por inibir o plantio de diversas culturas, durante o ano ou na época das águas, que são de grande importância nacional (DUARTE et al, 2013).

As culturas como feijão, milho e soja apresentam grande importância no cenário nacional, sendo evidenciadas por suas particularidades, que promovem o sucesso da produção. (DUTRA et al., 2015; FRANCISCO et al., 2017; MORAIS et al., 2017). Garcia et al. (2012), citam o feijão como um dos principais alimentos de sustento básico para a maioria da população nacional. Kopp et al. (2016) evidenciam a importância do milho com sua utilização em diversas áreas, como na alimentação animal e humana, na produção de óleos e, em alguns países, na fabricação de etanol. Em relação à cultura da soja, Carvalho et al. (2012) afirmam que seu crescimento acelerado está ocupando áreas que antes eram cultivas com outras espécies, especialmente na região do Nordeste.

Segundo dados da CONAB (2017), o plantio de feijão na ultima safra aponta crescimento na área plantada de $13,4 \%$ em relação à safra passada, aproximadamente 1.110 mil hectares. A produtividade média obtida para essa cultura está estimada em 1.249 $\mathrm{kg} \mathrm{ha}{ }^{-1}$, na média nacional, $18,2 \%$ acima da produtividade obtida na última temporada. Na produção de milho a área estimada apresentou incremento nacional de $3,1 \%$ em relação a safra anterior, incentivado pelo comportamento agressivo dos produtores da região Centro-Sul, que aumentaram em 6\% a área de plantio. O total da área plantada com milho primeira safra, para o período 2016/2017, atingiu 5.522 mil hectares, contra 5.357 mil, observados no ano anterior. A produção atinge o montante de 30.313 mil toneladas, representando incremento de $17,7 \%$ em relação à safra passada. A soja alcançou performance recorde de safra brasileira, apresentando um crescimento na área plantada de $1,9 \%$ e uma produção de 113.930 mil toneladas.

Em um contexto geral, para o bom desenvolvimento das espécies citadas acima, a disponibilidade de água é um fator de suma importância. Tem sido relatada a sensibilidade do feijão ao estresse hídrico, principalmente em virtude da baixa capacidade de recuperação após a deficiência hídrica e sistema radicular pouco desenvolvido (FRANCISCO et al., 2016). No milho sua alta variabilidade no rendimento tem como causa principal a deficiência hídrica devido às instabilidades no regime de chuvas, tal realidade pode ser observada devido ao fato de que a cultura é muito exigente em água (SOUZA et al., 2015). Na cultura da soja a deficiência hídrica no início do ciclo, causa forte redução na emissão de novos ramos reduzindo potencialmente o número de nós que iriam produzir legumes (GAVA et al., 2016).

Dada a importância da água para o melhor desenvolvimento das culturas torna-se imprescindível estudos que compreendam as respostas fisiológicas das plantas em função da variação de disponibilidade hídrica (CHAVARRIA et al., 2015). Não é habitual que o solo ofereça ambiente ótimo para a germinação das sementes; quando ocorre deficiência hídrica o solo apresenta potenciais hídricos que dificultam a absorção da água necessária para a germinação. $O$ estresse hídrico logo após o plantio é um dos fatores abióticos que mais influência no processo germinativo, interferindo diretamente nas atividades enzimáticas da planta minimizando o rendimento das cultivares e causando prejuízo ao produtor (GARCIA et al, 2012).

Assim, o presente trabalho teve como objetivo simular condições de déficit hídrico, em laboratório, por meio de simulação com manitol, para a avaliação do desempenho fisiológico de genótipos de feijão, milho e soja.

\section{Material e Métodos}

O experimento foi desenvolvido no Laboratório da Universidade Estadual de Goiás, do Câmpus Ipameri (GO), no ano de 2015. Foram utilizadas 10 cultivares de feijão (BRS AGRESTE, BRS AMETISTA, BRS COMETA, BRS ESTILO, BRS MARFIM, BRS NOTÁVEL, BRS PÉROLA, BRS PONTAL, BRS SUBLIME, CNFC 10729 e CNFC 10762); 10 híbridos de milho, convencionais e transgênicos, (2B182PW, 2B587PW, 2B707PW, 30F35HR, 30F53YH, AG1051, BRS1055, BRS3061, B3646H e P38622YH); e 10 cultivares de soja transgênicas (Nidera 5959 INTACTA, 7338 INTACTA, Nidera 8490 RR, Nidera 7670 RR, 7209 INTACTA, 7901 RR, Nidera 7200, 7000 INTACTA, Nidera 7237 INTACTA, NA 5909 RG). 
As sementes destes genótipos foram submetidas à germinação sob condições de estresse hídrico, com os níveis $0,-0,6,-1,2,-1,8$ e $-2,4 \mathrm{MPa}$ de potencial osmótico, simulados com soluções de manitol $\left(\mathrm{C}_{6} \mathrm{H}_{14} \mathrm{O}_{6}\right)$, nas doses: 0 ; 44; 58; 89,17; 133,75 $\mathrm{g} \mathrm{L}^{-1}$. Para o cálculo das concentrações utilizou-se a fórmula de Van't Hoff: Yos = RTC, em que: Yos: potencial osmótico (atm); R: constante geral dos gases perfeitos (0,082 atm. $\left.\mathrm{L} \mathrm{mol}^{-1}{ }^{\circ} \mathrm{K}^{-1}\right)$; $\mathrm{T}$ : temperatura $\left({ }^{\circ} \mathrm{C}\right)$ e $\mathrm{C}$ : concentração $\left(\mathrm{mol} \mathrm{L}^{-1}\right)$.

Os experimentos foram dispostos em delineamento inteiramente casualizado (DIC), com cinco tratamentos (0, -0,6, -1,2, -1,8 e -2,4 MPa de potencial osmótico) e quatro repetições para cada genótipo. Foram dispostas 50 sementes de cada genótipo para germinar em três folhas de papel (Germitest,) umedecidas com 2,5 vezes a sua massa, com soluções osmóticas de manitol para proporcionar diferentes níveis de potencial osmótico nas sementes. Em seguida, as sementes foram depositadas sobre duas folhas e recobertas com uma terceira folha de papel; em seguida, enroladas e colocadas em uma câmara de germinação (BOD), com umidade de $92 \%$ e temperatura de $25^{\circ} \mathrm{C}$, permanecendo nesta condição por um período de dez dias.

A análise da germinação das sementes foi realizada segundo metodologia proposta pela RAS - Regras para Análise de Sementes (BRASIL, 1992), no décimo dia. Posteriormente, para a análise do teste de geminação, foi utilizado o critério de emissão de radícula e, para o desenvolvimento, medição da radícula e do hipocótilo das plântulas normais desenvolvidas.

Os dados obtidos foram submetidos à análise de variância e comparação entre as médias pelo teste de Scott-Knott, a 5\% de significância, e, então, realizadas as análises de regressão polinomial para as diferentes concentrações de manitol. Foram também realizados testes de análises descritivas e de normalidade (Shapiro-Wilk) para todas as variáveis, utilizando o programa estatístico SISVAR (FERREIRA, 2008).

\section{Resultados e Discussão}

O resumo da análise de variância para as variáveis germinação, tamanho da radícula e do hipocótilo é mostrado na Tabela 1. Houve um efeito significativo entre o estresse hídrico com essas variáveis, demonstrando uma influência de diferentes níveis de déficit hídrico na semente de feijão, milho e soja.

$\mathrm{O}$ percentual de germinação em função do potencial osmótico está representado na Figura 1A, onde foi verificado redução da germinação com o aumento do déficit hídrico para as três culturas em questão. A redução na germinação de sementes com o aumento das concentrações de manitol pode ser atribuída à redução da velocidade e quantidade de água absorvida pelas sementes, uma vez que o déficit hídrico durante a germinação inibe a absorção de água pelos tecidos, dificultando assim o início da germinação das sementes (KAPPES et al., 2010, PELEGRINI et al., 2013).

Segundo Willadino e Camara (2010), as respostas das sementes ao estresse hídrico induzido por sais podem ser influenciadas pelas características da espécie, seu estádio de desenvolvimento, idade e o genótipo estudado. $\mathrm{O}$ efeito da salinidade sobre as plantas afeta dois componentes: o componente osmótico, resultante da elevada concentração de solutos na solução do solo e indução do déficit hídrico pela redução do potencial osmótico; e o componente iônico, decorrente da elevação dos teores de $\mathrm{Na}^{+}$e $\mathrm{Cl}^{-}$e da redução da relação $\mathrm{K}^{+} / \mathrm{Na}^{+}$e outros nutrientes.

Tabela 1 - Quadrados médios da análise de variância para estresse hídrico e doses de manitol, para as variáveis percentagem de germinação (GERM), comprimento do hipocótilo (HIP) e da radícula (RAD), para as culturas do feijão, milho e soja.

\begin{tabular}{|c|c|c|c|c|c|}
\hline Cultura & F.V & GL & GERM & HIP & RAD \\
\hline \multirow{4}{*}{ 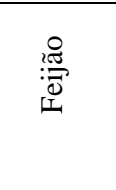 } & Estresse & 4 & $141,08 * *$ & $13,58 * *$ & $19,70 * *$ \\
\hline & Doses & 19 & 0,31 & 0,14 & 0,06 \\
\hline & Erro & 76 & 0,16 & 0,11 & 0,12 \\
\hline & \multicolumn{2}{|c|}{$\mathrm{CV}(\%)$} & 6,34 & 17,44 & 25,29 \\
\hline \multirow{4}{*}{$\stackrel{ᄋ}{\equiv}$} & Estresse & 4 & $12,93 * *$ & $15,84 * *$ & $28,73^{* *}$ \\
\hline & Doses & 19 & 0,55 & 0,54 & 0,40 \\
\hline & Erro & 76 & 0,17 & 0,17 & 0,16 \\
\hline & \multicolumn{2}{|c|}{$\mathrm{CV}(\%)$} & 5,66 & 20,49 & 27,14 \\
\hline \multirow{4}{*}{$\frac{\pi}{\delta}$} & Estresse & 4 & $3,39 * *$ & $14,48 * *$ & $29,99 * *$ \\
\hline & Doses & 19 & 0,53 & 0,21 & 0,20 \\
\hline & Erro & 76 & 0,13 & 0,25 & 0,25 \\
\hline & \multicolumn{2}{|c|}{$\mathrm{CV}(\%)$} & 8,10 & 21,34 & 35,27 \\
\hline
\end{tabular}

** significativo a $1 \%$ de probabilidade pelo teste $\mathrm{F} ; \mathrm{CV} \%$ - coeficiente de variação. 
O feijão se mostrou como a cultura mais sensível ao déficit hídrico, apresentando comportamento linear, corroborando com os resultados de Garcia et al. (2012) para o genótipo de feijoeiro BAF 09, e com Coelho et al. (2010) estudando a cultivar BRS Pérola.

Em contrapartida, Duarte et al. (2013) verificaram um decréscimo da germinação de plântulas de feijoeiro a partir do potencial hídrico de -0,6 $\mathrm{MPa}$, sendo que as cultivares BRS Esplendor e BRS Agreste se destacaram como tolerantes ao déficit hídrico e as cultivares BRS Estilo, BRS Pérola, BRS Pontal e BRS Cometa demostraram sensibilidade à restrição hídrica. Dantas et al. (2007) verificaram que o grupo Mulatinho é mais sensível ao estresse hídrico quando comparado ao feijão carioca, com germinação nula em -0,48 MPa.

$\mathrm{O}$ milho e a soja se mostraram mais resistente ao estresse hídrico quando comparadas ao feijão, com valores de germinação satisfatórios até o potencial osmótico de -1,2 Mpa, com redução de apenas 9,9\% da germinação para ambas as culturas. Isso difere do encontrado por Kappes et al. (2010) para milho, que causou redução de $45 \%$ da germinação para este mesmo potencial hídrico em híbridos simples comerciais, e do encontrado por Soares et al. (2015), em diferentes cultivares de soja, com inibição da germinação no potencial de -0,6 MPa. Apesar da capacidade de germinação afetada, de maneira geral, estas culturas superaram as condições restritas de disponibilidade de água (KAPPES et al., 2010).

Soares et al. (2015) afirmam que a germinação das sementes pode ser severamente afetada pela baixa disponibilidade de água e consequente baixo potencial hídrico, principalmente em solos que exibem maiores teores de sais.

Para o crescimento do hipocótilo, houve redução de $41,46 \%, 70,19 \%$ e $58,7 \%$ para milho, soja e feijão, respectivamente, a $-0,6 \mathrm{Mpa}$ (Figura $1 \mathrm{~B}$ ). No potencial de -2,4 MPa o crescimento radicular foi inibido para as três culturas. Resultado semelhante ao obtido por Garcia et al. (2012), onde a redução do potencial hídrico induzido por manitol afetou negativamente o desenvolvimento da radícula e da parte aérea do feijoeiro.

Os genótipos mais sensíveis à seca podem indicar menor capacidade destes cultivares em interligar diversos sinais ambientais à sinalização metabólica que regulam a expressão gênica durante o estresse, dificultando a sobrevivência e impossibilitando boa produtividade (CUSTÓDIO et al., 2009). Plântulas com habilidade de crescer raízes em condições de déficit hídrico conseguem manter os tecidos mais hidratados que o meio circundante através do ajustamento osmótico (ECHER et al., 2010).

A germinação de sementes em diferentes potenciais osmóticos torna-se dependente do material genético utilizado, sendo que o fator genótipo é determinante quanto à tolerância ou não ao déficit hídrico no solo em condições de campo (KAPPES et al., 2010).

A redução no potencial hídrico afetou negativamente o crescimento do hipocótilo para as três culturas, demonstrando ter seu desenvolvimento prejudicado quando submetidos à ambientes em déficit hídrico, conforme Figura 2A. O feijoeiro foi a cultura que apresentou menor redução do hipocótilo a -0,6 Mpa $(18,18 \%)$, enquanto o milho e a soja apresentaram redução de $35,91 \%$ e $28,48 \%$, respectivamente.

Em trabalho realizado por Kappes et al. (2010), o milho teve 49,23 a $74,51 \%$ de redução do comprimento da parte aérea, porém essa redução variou de acordo com o genótipo testado, com os híbridos XB 6012 e XB 9003 apresentando melhor desempenho. Essa variação da redução do hipocótilo em função do genótipo também foi encontrada por Dantas et al. (2007) em feijoeiro, com $55 \%$ de redução do comprimento da parte aérea no grupo Carioca e de $95 \%$ no grupo Mulatinho a -0,48 MPa, e por Duarte et al. (2013), sendo que genótipos tolerantes (BRS Agreste e BRS Ametista) apresentaram $7,63 \%$ da redução do comprimento do hipocótilo e genótipos sensíveis até $72 \%$ no potencial de -0,6 MPa (BRS Cometa e BRS Esplendor).

O estresse hídrico causa redução do potencial hídrico da célula, e consequente diminuição da pressão de turgor, afetando negativamente a expansão e o crescimento celular, o metabolismo, crescimento e estabelecimento das plântulas (JALEEL et al. 2009), reduzindo, desta forma, o crescimento do hipocótilo e da radícula.

Duarte et al. (2013) observaram que os genótipos de feijoeiro BRS Agreste, BRS Ametista, BRS Estilo e BRS Marfim aumentaram o crescimento radicular sob potencial hídrico de -0,6 MPa, enquanto Dantas et al. (2007) notaram aumento do comprimento da parte aérea do grupo Carioca no potencial hídrico de -0,12 MPa. Tal fato indica que estes genótipos podem ser mais tolerantes à deficiência hídrica que as outras cultivares testadas, por desenvolver o sistema radicular a fim de aumentar a absorção de água em condições de estresse hídrico.

Somente para o milho notou-se um aumento da razão do comprimento da radícula/hipocótilo, com razão de 1,15 no potencial de $-0,31 \mathrm{MPa}$, demonstrado na Figura 2B. Este efeito se deve ao fato de que plantas submetidas ao estresse hídrico podem promover um maior desenvolvimento do sistema radicular para absorver água em maiores profundidades, enquanto plantas com disponibilidade hídrica adequada alcançam maior desenvolvimento da parte aérea, como ocorre na cultura da canola (ÁVILA et al., 2007) e com alguns cultivares de algodoeiro (ECHER et al., 2010). 

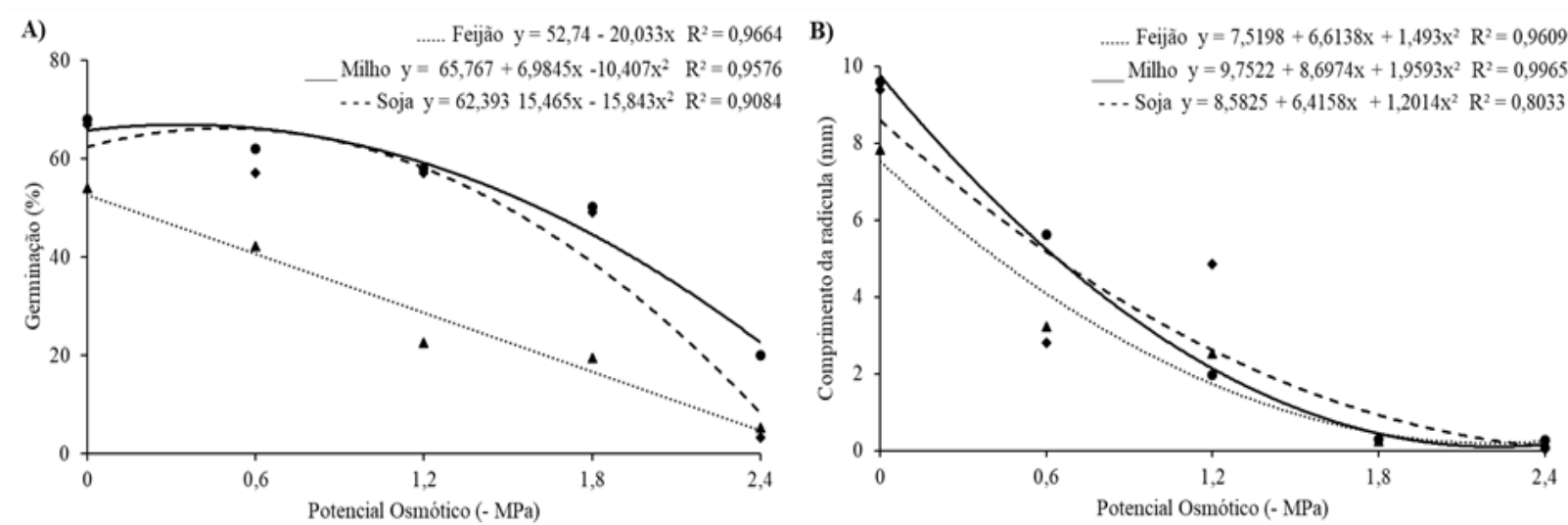

Figura 1. Percentagem de germinação (A) e comprimento da radícula (B), em função dos diferentes níveis de potenciais osmóticos.
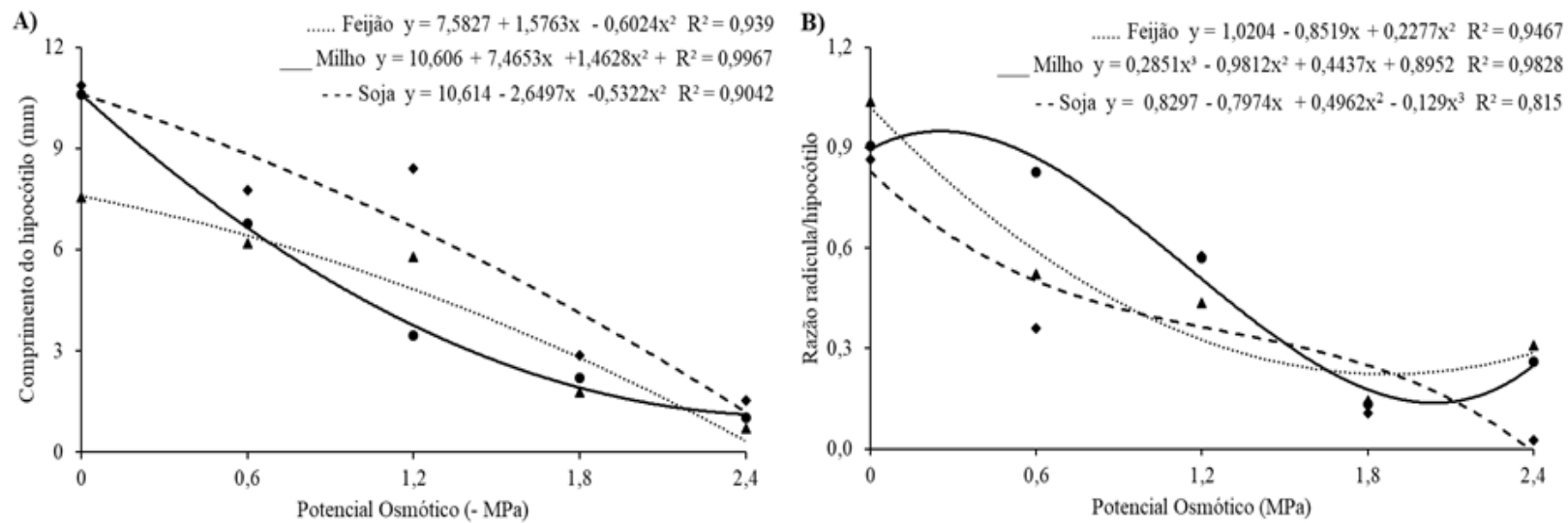

Figura 2. Comprimento do hipocótilo (A) e relação radícula/hipocótilo (B), em função dos diferentes níveis de potencial osmótico.

Rauf et al. (2007) estudando estresse hídrico em sementes de trigo, notaram correlação positiva e altamente significativa da porcentagem de germinação com o comprimento da parte aérea, comprimento das raízes, comprimento do coleóptilo, peso fresco e seco da raiz; e correlação negativa e não significativa entre a percentagem de germinação e a razão de raiz/parte aérea.

De acordo com Ávila et al. (2007), o estresse hídrico contribui para a diminuição do potencial germinativo das sementes, significando que para cada espécie existe um valor de potencial hídrico no solo abaixo do qual a germinação não ocorre. Para as três culturas estudadas, pode-se afirmar que potenciais hídricos abaixo de $-2,4$ MPa torna quase nula a germinação, crescimento do hipocótilo e da radícula, não sendo recomendado a semeadura quando o solo estiver abaixo deste potencial hídrico.

Devido às variações climáticas se tornarem mais frequentes, estudos relacionados ao estresse hídrico se tornam cada vez mais importantes para produção de grãos em áreas com déficit hídrico. Somado a esse fator, parâmetros relacionados à semente determinam o sucesso e estabelecimento da lavoura e o aumento da produtividade agrícola.

\section{Conclusões}

A germinação e comprimento do hipocótilo e da radícula para feijão, milho e soja são reduzidos sob condições de estresse hídrico e salino induzidos por manitol.

As espécies estudadas revelam comportamentos diferenciados quanto à tolerância em condição de déficit hídrico.

O feijão se apresentou como a cultura de maior sensibilidade ao déficit hídrico, com redução da germinação, comprimento do hipocótilo e da radícula a $-0,6 \mathrm{MPa}$, enquanto sementes de milho e soja tiveram sua germinação afetada em potencias abaixo de $-1,2$ Mpa.

\section{Referências Bibliográficas}

ÁVILA, M. R.; BRACCINI, A. L.; SCAPIM, C. A.; FAGLIARI, J. R.; SANTOS, J. L. Influência do estresse hídrico simulado com manitol na germinação de sementes e crescimento de plântulas de canola. Revista Brasileira de Sementes, Maringá-RS, v. 29, n. 1, p. 98-106, 2007.

BRASIL/MAPA. MINISTÉRIO DA AGRICULTURA E REFORMA AGRÁRIA. Regras de análise de sementes. Brasília - DF: SNAD/ DND/CLAV. 1992. 365 p. 
CARVALHO, T. C.; SILVA, S. S.; SILVA, R. C.; PANOBIANCO, M. Germinação e desenvolvimento inicial de plântulas de soja convencional e sua derivada transgênica RR em condições de estresse salino. Ciência Rural, Santa MariaRS, v. 42, n. 8, p. 1366-1371, 2012.

CHAVARRIA, G.; DURIGON, M. R.; KLEIN, V. A.; KLEBER, H. Restrição fotossintética de plantas de soja sob variação de disponibilidade hídrica. Ciência Rural, Santa Maria-RS, v. 45, n. 8, p. 1387-1393, 2015.

COELHO, D. L. M.; AGOSTINI, E. A. T.; GUABERTO, L. M.; MACHADO NETO, N. B.; CUSTÓDIO, C. C. Estresse hídrico com diferentes osmóticos em sementes de feijão e expressão diferencial de proteínas durante a germinação. Acta Scientiarum Agronomy, Maringá-RS, v. 32, n. 3, p. 491-499, 2010 .

CONAB. COMPANHIA NACIONAL DE ABASTECIMENTO. Acompanhamento da Safra Brasileira de Grãos 2016/17: Nono Levantamento-Junho/2017. Dados de safra. Disponível em: http://www.conab.gov.br/. Acesso em: 18 jun. 2017.

CUSTÓDIO, C. C.; SALOMÃO, G. R.; MACHADO NETO, N. B. Estresse hídrico na germinação e vigor de sementes de feijão submetidas à diferentes soluções osmóticas. Revista Ciência Agronômica, Fortaleza-CE, v. 40, n. 4, p. 617-623, 2009.

DANTAS, B. F.; RIBEIRO, L. S.; ARAGÃO, C. A. Germination, initial growth and cotyledon protein content of bean cultivars under salinity stress. Revista Brasileira de Sementes, Londrina-PR, v. 29, n. 2, p. 106-110, 2007.

DUARTE, D. M.; SILVA, D. C.; ROCHA, E. C.; PEREIRA, H. S.; RODRIGUES, F. Simulação de déficit hídrico em diferentes genótipos de feijão pela diminuição do potencial osmótico. Revista Processos Químicos, Anápolis-GO, v. 13, p. 35-41, 2013.

DUTRA, A. F.; MELO, A. S.; FILGUEIRAS, L. M. B.; SILVA, A. R. F.; OLIVEIRA, I. M.; BRITO, M. E. B. Parâmetros fisiológicos e componentes de produção de feijãocaupi cultivado sob deficiência hídrica. Revista Brasileira de Ciências Agrárias, Recife-PE, v. 10, n. 2, p. 189-197, 2015.

ECHER, F. R.; CUSTÓDIO, C. C.; HOSSOMI, S. T.; DOMINATO, J. C.; MACHADO NETO, N. B. Estresse hídrico induzido por manitol em cultivares de algodão. Revista Ciência Agronômica, Fortaleza-CE, v. 41, n. 4, p. 638-645, 2010.

FERREIRA, D. F. SISVAR: um programa para análises e ensino de estatística. Revista Symposium, Recife-PE, v. 6, p. 36-41, 2008.

FRANCISCO, P. R. M.; BANDEIRA, M. M.; SANTOS, D.; PEREIRA, F. C.; GONÇALVES, J. L. G. Aptidão climática da cultura do feijão comum (Phaseolus vulgaris) para o estado da Paraíba. Revista Brasileira de Climatologia, Paraíba-PB, v. 19, n. 1, p. 366-378. 2016.

FRANCISCO, P. R. M.; SANTOS, D.; GUIMARÃES, C. L.; ARAUJO, S. R. D.; OLIVEIRA, F. P. Aptidão climática do milho (Zea mays L.) para o estado da Paraíba. Revista de Geografia, Recife-PE, v. 34, n. 1, p. 290-305, 2017.
GARCIA, S. H.; ROZZETO, D. S.; COIMBRA, J. L. M.; GUIDOLIN, A. F. Simulação de estresse hídrico em feijão pela diminuição do potencial osmótico. Revista de Ciências Agroveterinárias, Lages-MG, v. 11, n. 1, p. 35-41, 2012.

GAVA, R.; FRIZZONE, J. A.; SNYDER, R. L.; ALMEIDA, B. M.; FREITAS, P. S. L.; REZENDE, R. Estratégias de manejo de déficit hídrico na irrigação da cultura da soja. Brazilian Journal of Biosystems Engineering, Tupã-SP, v. 10, n. 3, p. 305-315, 2016.

JALEEL, C. A.; MANIVANNAN, P.; WASHID, A.; PANNEERSELVAM, R. Drought stress in plants: a review on morphological characteristics and pigments composition. International Journal of Agriculture Biology, Índia, v. 11, n. 1, p. 100-105, 2009.

KAPPES, C.; ANDRADE, J. A.; HAGA, K. I.; FERREIRA, J, P.; ARF, M. V. Germinação, vigor de sementes e crescimento de plântulas de milho sob condições de déficit hídrico. Scientia Agraria, Curitiba-PR, v. 11, n. 2, p.125-134, 2010.

KIRSANOVA, D.; ZADOROZHNAYAA, O.; KRASHENINNIKOV, A.; KOMAROVA, N.; POPOV, A.; LEGINA, A. Water toxicity evaluation in terms of bioassay with an Electronic Tongue. Sensors and Actuators, Rússia, v. 179, p. 282-286, 2013.

KOPP, L. M.; PEITER, M. X.; BEN, L. H. B.; NOGUEIRA, H. M. C. D. M.; PADRON, R. A. R.; ROBAINA, A. D.; BUSKE, T. C. Simulação da necessidade hídrica e estimativa de produtividade para cultura do milho em municípios do RS. Revista Brasileira de Milho e Sorgo, Pelotas-RS, v. 14, n. 2, p. 235-246, 2016.

MEIRELES, A. C. M.; ANDRADE, E. M.; CHAVES, L. C. G.; FRISCHKORN, H.; CRISOSTOMO, L. A. A new proposal of the classification of irrigation water. Revista Ciência Agronômica, Fortaleza-CE, v. 41, n. 3, p. 349-357, 2010.

MORAIS, W. A.; CUNHA, F. N.; SOARES, F. A. L.; TEIXEIRA, M. B.; SILVA, N. F.; COSTA, C. T. S. Avaliação das características de produção do feijoeiro submetidos a variações de lâminas de irrigação e doses de adubação. Revista Brasileira de Agricultura Irrigada, Fortaleza-CE, v.11, n. 3, p. 1389-1397, 2017.

PELEGRINI, L. L.; BORCIONI, E.; NOGUEIRA, A. C.; KOEHLER, H. R.; QUOIRIN, M. G. G. Efeito do estresse hídrico simulado com $\mathrm{NaCl}$, manitol e PEG (6000) na germinação de sementes de Erythrina falcata Benth. Ciência Florestal, Santa Maria-RS, v. 23, n. 2, p.511-519, 2013.

RAUF, M.; MUNIR, M.; UL HASSAN, M.; AHMAD, M.; AFZAL, M. Performance of wheat genotypes under osmotic stress at germination and early seedling growth stage. African Journal of Biotechnology, Kenia, v. 6, n. 8, p. 971-975, 2007.

RODRIGUES, G. Z. P.; DALZOCHIO, T.; GEHLEN, G. Uso do bioensaio com Allium cepa L. e análises físico-químicas e microbiológicas para avaliação da qualidade do Rio da Ilha, RS, Brasil. Acta Toxicologica Argentina, Buenos Aires, v. 24, n. 2, p. 97-104, 2016

SOARES, M. M.; SANTOS JUNIOR, H. C.; SIMÕES, M. G.; PAZZIN, D.; SILVA, L. L. Estresse hídrico e salino em sementes de soja classificadas em diferentes tamanhos. 
Pesquisa Agropecuária Tropical, Goiânia-GO, v. 45, n. 4, p. 370-378, 2015.

SOUZA, L. C.; MELO, N. C.; SIQUEIRA, J. A. M.; SILVA, V. F. A.; OLIVEIRA NETO, C. F. Comportamento bioquímico no milho submetido ao déficit hídrico e a diferentes concentrações de silício. Revista Agrarian, Dourados-MG, v. 8, n. 29, p. 260-267, 2015.
TAIZ, L.; ZEIGER, E. Fisiologia Vegetal, 4. ed., Artmed, $2008.820 \mathrm{p}$

WILLADINO, L.; CAMARA, T. R. Tolerância das plantas à salinidade: aspectos fisiológicos e bioquímicos. Enciclopédia Biosfera, Goiânia-GO, v. 6, n. 11, p. 1-23, 2010. 